\title{
DETERMINACION DE LAS SANCIONES EN LA LEY DE RESPONSABILIDAD PENAL JUVENIL Y PROCEDIMIENTO APLICABLE
}

\author{
María Inés Horvitz Lennon*
}

1. Breve introducción previa; 2. De las sanciones y su finalidad; 3. Función y fines de la sanción penal juvenil y determinación de la pena; 4. Las reglas de determinación de las sanciones en la LRPA: 4.1 Reglas referidas a la duración de las penas: 4.1.1 Regla general que opera en un primer nivel de determinación. Limites temporales absolutos; 4.1.2 Reglas que operan en un segundo nivel de determinación; 4.1.3 Situación especial de las penas privativas de libertad; 4.2. Reglas de determinación de la naturaleza de las penas: 4.2.1. Primera fase del procedimiento de individualización de la pena; 4.2.2. Segunda fase del proceso de individualización; 5. Procedimientos aplicables al ámbito sancionatorio juvenil: 5.1. Regla general; 5.2. Regla especial

\section{Breve introducción previa}

La nueva Ley sobre responsabilidad penal de adolescentes (LRPA), $\mathrm{N}^{\circ} 20.084$, publicada en el Diario Oficial el 7 de Diciembre de 2005, y cuya entrada en vigencia se defirió en 6 meses, crea un sistema especial de responsabilidad penal para los adolescentes entre 14 y 17 años, poniendo fin al sistema binario imputabilidad/ inimputabilidad que establecieron los arts. $10 \mathrm{~N}^{\circ} 2$ y 3 del Código Penal basado en la declaración judicial sobre el discernimiento del menor, y somete el enjuiciamiento penal del adolescente a las garantías del debido proceso existentes con anterioridad para los adultos, corrigiendo así un defecto insostenible del ordenamiento positivo chileno ampliamente criticado por la doctrina.

La Ley recoge los principios de la Convención sobre los Derechos del Niño ratificada por Chile en 1990, y con ello traza una línea de continuidad entre la infancia y la condición de ciudadanía. El "interés superior del niño" no sólo debe orientar sino limitar el poder punitivo estatal y el conjunto de las políticas públicas enfocadas hacia los niños y adolescentes; es decir, la edad del joven sólo puede constituir un factor de aseguramiento reforzado del goce de sus derechos y jamás de exclusión de su goce actual y efectivo. La nueva ley busca terminar con el tradicional paradigma pseudopaternalista del derecho de menores y reemplazarlo por el de la responsabilidad diferenciada (respecto de los adultos), sistema incomparablemente más garantista y más respetuoso del adolescente que el viejo sistema "pedagógico" de "medidas" impuestas informal y arbitrariamente por el juez de menores.

\footnotetext{
* Profesora Asociada Derecho Penal. Directora Centro de Estudios de la Justicia Facultad de Derecho Universidad de Chile. Este trabajo fue realizado en el marco de una consultoría contratada por la Defensoría Penal Pública. La autora agradece al Defensor Nacional su autorización para la publicación del mismo.
} 
Horvitz - Determinación de las sanciones en la ley de responsabilidad penal juvenil...

No obstante que las innovaciones jurídicas de la ley son notorias, como el señalado reconocimiento al adolescente de su calidad de sujetos de derechos y garantías penales y procesales, nos parece que buena parte de la regulación no da cuenta de los aportes y restricciones que la legislación comparada ha ido incorporando en el ámbito sancionatorio juvenil, en el que el proceso de desarrollo del joven demanda al Estado no sólo reacciones diferenciadas a las previstas para los adultos infractores, sino también un menor catálogo de conductas punibles. En suma, un "derecho penal mínimo" y menos severo, tanto en la tipificación de los delitos cuanto en la cantidad y calidad de las sanciones. Ello significa comprender la delincuencia juvenil más como un problema social antes que criminal, que, en lo posible, debe ser enfrentado primordialmente con políticas de asistencia o con medios extrapenales de conciliación de los conflictos, antes que con estériles medidas represivas ${ }^{1}$.

Por consiguiente, el joven no debe responder penalmente por los mismos comportamientos que resultan reprochables en un adulto ${ }^{2}$, pues aquél todavía se halla en medio del proceso de internalización y asunción de los mandatos y prohibiciones que constituyen la base de las infracciones penales y, por otro lado, no parece razonable hacer exigibles bajo amenaza penal ciertas conductas que presuponen la calidad de ser portador competente de roles en el tráfico jurídico-social y económico cuando el propio derecho no considera a los jóvenes plenamente capaces para desempeñarse en ellos ${ }^{3}$. Por ello, autores especialistas en esta materia consideran problemática una utilización universal de la categoría sistemática jurídico penal de la "culpabilidad" en el derecho penal de los adolescentes, pues los presupuestos e implicancias de dicho concepto no se ajustan a la situación psicosocial de éstos ${ }^{4}$.

En consecuencia, un primer defecto legislativo de importancia de la nueva regulación se aprecia en la configuración del ámbito de conductas punibles. Ya en el artículo $1^{\circ}$ de la Ley se destaca que objeto de ella es la regulación de la responsabilidad penal de los adolescentes por los delitos que cometan, el procedimiento para la averiguación y establecimiento de dicha responsabilidad, la determinación de las sanciones procedentes y la forma de ejecución de éstas". No obstante, en el segundo inciso se efectúa una remisión subsidiaria, para "lo no previsto por ella", a las disposiciones del Código Penal y leyes penales especiales. Es decir, aunque se reconoce que al adolescente debe exigírsele una responsabilidad especial adecuada a su condición de sujeto en desarrollo, el tratamiento diferenciado se concreta fundamentalmente en el nivel de las sanciones

\footnotetext{
${ }^{1}$ Cfr. Ferrajoli, L.: Prefacio del documento Infancia, Ley y Democracia, que contiene el Anteproyecto de Ley sobre Responsabilidad por Infracciones Juveniles a la Ley penal, UNICEF/ Ministerio de Justicia, Julio 1998, pp. 10-11.

2 Por ello, el Anteproyecto de Ley sobre responsabilidad por infracciones juveniles a la ley penal, presentado en su momento por el Ministerio de Justicia y el Fondo de Naciones Unidas para la Infancia (UNICEF), contemplaba, en su art. $4^{\circ}$, un catálogo taxativo y único de infracciones juveniles a la ley penal.

${ }^{3}$ Piénsese, por ejemplo, en todos aquellos actos o declaraciones de voluntad con relevancia socioeconómica y la disposición del art. 1447 del Código Civil.

${ }^{4}$ Cfr. Albrecht, (P.A), El derecho penal de menores, (trad. Juan Bustos Ramírez), PPU, Barcelona, 1990, p. 122. Kaiser señala: "Primeramente es el pensamiento de protección; consecuencia o correlato (de ello) es la mayor tolerancia", lo que requiere una categoría sistemática interpretativa de culpabilidad específica del menor (Cfr. Gesellschaft, Jugend und Recht, 1977, pp. 45 y ss.).
} 
aplicables, no en el de la tipificación normativa. Por tanto, la remisión al Código Penal implica que son sancionables a título de esta ley todos los crímenes y simples delitos de la legislación penal de adultos, con excepción de las faltas no señaladas en el inciso $3^{\circ}$ del artículo $1^{\circ}$ de la Ley 20.084. Las faltas no punibles por la Ley 20.084 se someten a un procedimiento especial ante los Tribunales de Familia y sólo cabe respecto de ellas la imposición de sanciones no privativas de libertad ${ }^{5}$.

Por consiguiente, se abandonó la idea original, plasmada en el Anteproyecto de Ley sobre Responsabilidad por Infracciones Juveniles a la Ley Penal ${ }^{6}$, que había optado por un catálogo taxativo y expreso de delitos, muy inferior al general del sistema penal chileno, pues entendía que la exigencia de responsabilidad penal debía ser más restringida que para los adultos al tratarse de personas -adolescentes- que están en pleno proceso de desarrollo de su conciencia y de su personalidad y en los que la intervención propiamente punitiva conlleva consecuencias desocializadoras muy desfavorables para su futura reintegración social.

En efecto, ya en el Proyecto de Ley remitido por el Gobierno al Parlamento se contemplaba un catálogo de delitos considerados "infracciones graves" y sólo si se estaba ante un delito perteneciente a esta categoría podía imponerse una pena privativa de libertad, así como una medida cautelar de internación provisoria durante el proceso penal. Finalmente, se abandonó también la distinción entre infracciones graves y no graves y se siguió un modelo punitivo más amplio, como el español, que remite expresamente al Código Penal y a las leyes penales especiales. Es decir, no sólo se puede castigar a un adolescente por cualquier crimen o simple delito (las faltas, sólo en algunos casos) que esté contemplado como tal en el ordenamiento jurídico chileno vigente, sino que, además, se pueden imponer penas privativas de libertad en todo ese ámbito.

\footnotetext{
5 Vid. el párrafo $4^{\circ}$ del Título IV de la Ley 19.968 que establece el "procedimiento contravencional ante los Tribunales de Familia" y las sanciones que se contemplan en el artículo $102 \mathrm{~J}$ del citado cuerpo legal. Resulta interesante la observación de Berríos quien denuncia que, por la vía del desacato judicial (art. 240 inciso $2^{\circ}$ del Código de Procedimiento Civil) podría llegarse al internamiento en régimen semicerrado, pues la pena de tal desacato queda dentro del marco de la regla $4^{a}$ del art. 23 LRPA (Cfr. Berríos, G., "El nuevo sistema de justicia penal para adolescentes", en Revista de Estudios de la Justicia No 6, Facultad de Derecho U. de Chile, 2005, pp. 161 y ss.).

6 Sobre este Anteproyecto, vid. nota 1; también, Cillero/Bernales, "Derechos humanos de la infancia/adolescencia en la "justicia penal de menores de Chile: evaluación y perspectivas", en Revista de Derechos del Niño, No 1, UDP, 2002, pp. 33 y ss.

7 En el Mensaje No 68-347, remitido a la Cámara de Diputados el 2 de Agosto de 2002, se señalaba que "[r]especto a los tipos penales, se excluye a la mayoría de las faltas de la responsabilidad y sanciones contenidas en esta ley y se establece una categoría taxativa de infracciones de carácter grave que serán las únicas a las cuales se podrá aplicar, como último recurso, una sanción privativa de libertad". Esto es, se hacen punibles prácticamente los mismos hechos que constituyen delitos para los adultos, sólo que las penas privativas de libertad únicamente podrían aplicarse respecto de una categoría especial de ellos. Así, el art. 7 del Proyecto contemplaba, entre otras figuras, el homicidio, la violación, el secuestro y las distintas figuras graves de robo. El segundo informe de la Comisión de Constitución, Legislación, Justicia y Reglamentos del Senado da cuenta de la evolución de criterios habida en la misma hasta llegar al sistema de incriminación que consagra la Ley 20.084.
} 
Horvitz - Determinación de las sanciones en la ley de responsabilidad penal juvenil...

\section{De las sanciones y su finalidad}

El art. $6^{\circ}$ de la LRPA establece una "escala general" de sanciones para los adolescentes, "en sustitución de las penas contempladas en el Código Penal y en las leyes complementarias". Tal escala distingue, primeramente, entre las penas de delitos, penas de faltas $\mathrm{y}$, finalmente, una pena accesoria. Se advierte inmediatamente que existen dos penas privativas de libertad, sólo aplicables a los delitos: la internación con programa de reinserción social en régimen cerrado o semicerrado. También se contemplan dos penas con mayor o menor intensidad de control y asistencia socioeducativa del adolescente, la libertad asistida y la libertad asistida especial, y dos penas comunes a los delitos y faltas: la prestación de servicios en beneficio de la comunidad y la reparación del daño causado. Las faltas tienen asignadas, además de las dos anteriores, la multa y la amonestación. Se prevé como pena accesoria la prohibición de conducir vehículos motorizados, y si resulta necesario en atención a las circunstancias, el juez tiene la facultad, también como pena accesoria, de someter al adolescente a tratamientos de rehabilitación por adicción a las drogas o al alcohol (art. 7 LRPA).

De modo excepcional en la legislación nacional, la LRPA define expresamente la finalidad de las sanciones "y otras consecuencias" que establece dicha ley y señala que ellas tienen por objeto hacer efectiva la responsabilidad de los adolescentes por los hechos delictivos que cometan, de tal manera que la sanción forme parte de una intervención socioeducativa amplia y orientada a la plena integración social (art. 20 LRPA). Pareciera, entonces, que las sanciones en este ámbito tienen componentes tanto retributivos como preventivo-especiales, aunque con mayor preponderancia de esta última finalidad atendida la importancia que la ley confiere a la dimensión asistencial en el proceso de reinserción social del niño, circunstancia que -como veremos- jugará un papel principal a la hora de seleccionar la naturaleza y extensión de la sanción aplicable. Precisados los fines que se persiguen con la imposición de una sanción, podrá entonces determinarse cuál será la más apta o adecuada en el caso concreto y fijar su quantum a través de los factores relevantes señalados por la ley ${ }^{8}$.

Por todo lo anterior, nos parece pertinente hacer una breve digresión acerca de las relaciones entre fin o función de la pena y determinación de la sanción aplicable al caso concreto, esto es, la forma en que aquella finalidad opera al momento de decidir la naturaleza y el quantum de ésta. Dicho ejercicio nos parece necesario antes de examinar cada uno los criterios de determinación de pena establecidos por la LRPA y su coherencia con la función asignada por el legislador a las penas en el ámbito de la criminalidad juvenil

\section{Función y fines de la sanción penal juvenil y determinación de la pena.}

La principal tarea de la determinación de la pena es la identificación de los criterios que deben orientar la decisión y fijación de las circunstancias y factores que

\footnotetext{
${ }^{8}$ Vid. en general, sobre ello: Ziffer, P., Lineamientos de la determinación de la pena, Ad-Hoc, Buenos Aires, 1996.
} 
deben o no deben ser consideradas por el juez al momento de imponer la pena concreta, proceso que suele ser designado como individualización de la pena. En él tiene gran importancia la función que se asigne a la pena en las distintas fases en que ella opera: en su conminación abstracta, en su imposición judicial, o en su ejecución administrativa. En dicho proceso de individualización, el juez debe aplicar los criterios establecidos en la ley para cuya interpretación será de importante auxilio la función atribuida a la pena. Así lo señala expresamente el inciso $2^{\circ}$ del artículo 25 de la LRPA, que sienta la importancia hermenéutica del artículo 20 del mismo cuerpo legal y la necesidad de una resolución motivada que se haga cargo de tales finalidades.

En la determinación de la pena operan valoraciones de diferentes clases, pues en ella concurren intereses contrapuestos que es necesario compatibilizar, como son los del autor, de la víctima y los de la sociedad interesada en la confirmación de sus normas. Esto hace que sólo se pueda arribar a una solución satisfactoria y adecuada a través de una argumentación conforme a principios y reglas racionalmente fundados. En este sentido, una regla que señale que la privación de libertad se utilizará sólo como medida de último recurso (art. 26 inciso $1^{\circ}$ LRPA) juega como criterio general de determinación punitiva basado en consideraciones preventivo-especiales particularmente preponderantes en el ámbito de la criminalidad juvenil, de modo que aquélla constituye un lineamiento fundamental en esta materia. Tal sería la forma de dar contenido, entre varios posibles, al criterio interpretativo general de la LRPA del interés superior del adolescente (art. 2 inciso $1^{\circ}$ LRPA).

La cuestión más relevante a la hora de escoger un sistema de determinación de pena es su capacidad para predecir, del modo más seguro posible, la pena aplicable a un caso concreto. La previsibilidad de las decisiones judiciales, especialmente en el ámbito punitivo, es presentada como uno de los grandes valores que procura el principio de legalidad en sus diversas manifestaciones. Si se admite que no sólo los presupuestos de la responsabilidad penal y de la punibilidad (nullum crimen sine lege) sino también las consecuencias jurídicas del hecho punible (nullum poena sine lege) deben estar establecidas con anterioridad al hecho, ¿cómo sería posible considerar satisfecho este principio si, frente a un hecho concreto, sólo el juez pudiera decir cuál será la pena precisa a imponer en ese caso? Por otro lado, son conocidos doctrinalmente los argumentos en favor de una mayor discrecionalidad judicial a los efectos de "individualizar" la pena al caso concreto atendiendo a la gravedad del injusto, la culpabilidad del autor y los fines perseguidos por la pena'. En cualquier caso, la búsqueda de la mayor previsibilidad posible será siempre a costa de una menor individualización de la pena a las características concretas del hecho y su autor. En efecto, todo proceso de determinación de la pena implica la concurrencia de intereses contrapuestos- los del autor, los de la víctima y los de la sociedad interesada en la afirmación de sus normas-, los que deben ser compatibilizados por los entes estatales a cargo de la conminación, adjudicación y ejecución de la pena.

\footnotetext{
${ }_{9}^{9}$ Vid., por todos, Gracia Martín, L. (coord.): Lecciones de consecuencias jurídicas del delito, $2^{\mathrm{a}} \mathrm{ed}$., Tirant lo Blanch, Valencia, 2000, pp. 169 y ss.
} 
Horvitz - Determinación de las sanciones en la ley de responsabilidad penal juvenil...

Para posibilitar la concordancia de los fines de la pena en el caso concreto se han desarrollado diferentes construcciones. Por razones de pertinencia y economía, nos limitaremos a exponer aquélla que es dominante en Alemania y que grafica más paradigmáticamente la forma en que operan los diferentes fines de la pena, a partir de lo dispuesto en el parágrafo 46 del Código Penal alemán ${ }^{10}$. Se trata de la teoría del ámbito de juego, elaborada por la jurisprudencia alemana. Ella sostiene que existen "fronteras fluidas" que expresan un marco penal determinado por la culpabilidad. Tal marco de culpabilidad determinaría un umbral máximo y uno mínimo, por encima o por debajo de los cuales la pena ya no sería adecuada desde esta perspectiva. Dentro de dicho marco, la pena debe determinarse conforme a los fines de la pena y los criterios legales que atienden a esos mismos fines.

Más allá de las críticas que la doctrina alemana haya opuesto a esta y otras teorías, lo cierto es que ninguno de ellos prescinde de tales fines a la hora de postular algún modelo óptimo de determinación de la pena ${ }^{11}$.

\section{Las reglas de determinación de las sanciones en la LRPA}

El sistema de determinación de la pena de la LRPA es de carácter legal, dependiente del existente en el Código Penal, con un marco bastante extenso de individualización judicial, mucho más amplio que el del Código Penal.

La LRPA toma como criterio de partida las penas asignadas por el Código Penal y leyes especiales a los delitos cometidos por adultos. En una técnica legislativa compleja e inédita en nuestro sistema y que será, sin duda, fuente de innumerable controversia doctrinal y jurisprudencial, la LRPA establece el siguiente procedimiento individualizador: primero debe establecerse la duración de la sanción, recurriendo a la extensión temporal de las penas asignadas a los delitos contenidos en el Código Penal, y sólo una vez determinada aquélla puede designarse naturaleza de la sanción aplicable al caso.

${ }^{10}$ Art. 46 StGB. "Principios de la determinación de la pena:

(1) La culpabilidad del autor es el fundamento de la determinación de la pena. Se considerarán los efectos que son de esperar de la pena sobre la vida futura del autor en la sociedad.

(2) Al determinar la pena, el tribunal ponderará las circunstancias que hablan a favor o en contra del autor. Al respecto, se tomarán especialmente en consideración: los motivos y fines del autor; el ánimo que expresa el hecho, y la voluntad aplicada al hecho; la medida de la contrariedad al deber; la forma de ejecución y las consecuencias culpables del hecho; la vida anterior del autor, sus condiciones personales y económicas, así también como su conducta con posterioridad al hecho y, especialmente, sus esfuerzos por reparar los daños.

(3) No deben ser tomadas en consideración aquellas circunstancias que ya constituyen elementos del tipo legal."

Siguiendo el sistema alemán, los nuevos Códigos penales de Perú (1983), Colombia (1985), Bolivia (1987), Cuba (1992), Paraguay (1993) y Argentina (1994) sólo proporcionan ciertos criterios generales y dejan entregada su ponderación al juez.

11 Por todos, cfr. Roxin C., "Strafzumessung im Lichte der Strafzwecke", en Festschrift für Bockelmann, München, 1979, pp. 282 y ss. 
El artículo $6^{\circ}$ LRPA pareciera dar ciertas luces sobre el sistema de determinación de sanciones escogido, al precisar que la escala general de penas "juveniles" que contempla dicho cuerpo legal se plantea "en sustitución de las penas contempladas en el Código Penal y en las leyes complementarias (...)"; esto es, las reglas de determinación de las penas de la LRPA sólo se explican a partir de la necesidad de preservar la legalidad de las penas, principio irrenunciable de la intervención punitiva en un Estado de derecho democrático. Con la técnica legislativa seleccionada se busca únicamente evitar la repetición, con ciertas modificaciones, del catálogo de delitos y sanciones previsto en el Código Penal y leyes complementarias ${ }^{12}$. Si bien las ventajas de la técnica aludida son significativas, pues permite una importante economía legislativa sin sacrificar el principio de reserva legal, estimamos que las reglas de determinación de las sanciones que establece la ley resultan en buena parte imprecisas, redundantes e inconsistentes, dejando un amplio margen de discrecionalidad al tribunal para interpretarlas a su arbitrio, circunstancia que afecta peligrosamente el principio de certeza legal y seguridad jurídica.

Así, por ejemplo, los factores y circunstancias modificatorias de la responsabilidad penal juvenil operan en dos niveles: primero, en la fijación de la extensión o duración de la sanción (art. 22 LRPA) y, también, en la selección de la sanción aplicable dentro del marco penal determinado temporalmente (art. 24 LRPA). Esta situación podría determinar, prima facie, una doble consideración del mismo becho o circunstancia para la cuantificación de la sanción, procedimiento que se encuentra terminantemente proscrito en el caso de las circunstancias que agravan la responsabilidad penal, por imperativo del principio non bis in idem o prohibición de doble valoración recogido legalmente en el art. 63 del Código Penal. Ello ocurrirá normalmente cuando los criterios de determinación de la naturaleza de la pena ya hayan sido considerados para fijar la gravedad del delito y la posición o lugar de la consecuencia asignada al mismo dentro de la escala de penas. Volveremos sobre esta cuestión más adelante ${ }^{13}$.

Para un análisis más sistemático de las reglas para la determinación de las penas contempladas en la LRPA, efectuaremos una siguiente subdistinción entre reglas referidas a la duración de las penas y reglas referidas a la naturaleza de las penas dentro de los marcos de duración de las mismas.

Dentro de ambas clases de reglas estudiaremos cómo inciden los factores y circunstancias modificatorias de la responsabilidad penal juvenil.

\subsection{Reglas referidas a la duración de las penas}

\subsubsection{Regla general que opera en un primer nivel de determinación. Límites temporales absolutos.}

\footnotetext{
12 Situación que no ocurría en el Anteproyecto, pues en él se contemplaba un catálogo restringido y preciso de figuras punibles respecto de los adolescentes.

13 Vid. infra 4.2.
} 
Horvitz - Determinación de las sanciones en la ley de responsabilidad penal juvenil...

Como señaláramos, la naturaleza de la pena aplicable sólo podrá determinarse una vez precisada su duración. Conforme al artículo 21 LRPA, "y para los efectos de la presente ley, se entenderá que la pena asignada al delito cometido por un adolescente es la inferior en un grado al mínimo de los señalados por la ley para el ilícito correspondiente".

Esta regla significa que el legislador optó por establecer como marco abstracto de extensión de las sanciones juveniles el mismo que en la regulación anterior se deducía de la aplicación de la regla de atenuación de pena contenida en el inciso $1^{\circ}$ del artículo 72 del Código Penal. Cabe destacar, empero, que la ley establece un límite máximo temporal absoluto de las penas privativas de libertad que pueden imponerse a los adolescentes infractores de la ley penal. En efecto, el artículo 18 LRPA establece que las penas de internación en régimen cerrado y semicerrado, ambas con programa de reinserción social, no podrán exceder de cinco (5) años si el infractor adolescente tuviere menos de dieciséis (16) años, o de diez (10) años, si aquél tuviere más de esa edad (16 y 17 años).

Otros límites temporales absolutos que establece la ley se contemplan en el inciso $2^{\circ}$ del artículo 11 LRPA, respecto de los servicios en beneficio de la comunidad, e inciso final de los artículos 13 y 14, con relación a la libertad asistida y libertad asistida especial, respectivamente.

Por consiguiente, el sistema de determinación de penas en el ámbito juvenil es, en general, dependiente del sistema de penas para adultos y se define de acuerdo a los marcos sancionatorios del Código Penal, con la modificación señalada en el artículo 21 LRPA. Así, si un joven de 16 años es condenado como autor de un homicidio calificado, el punto de partida para la determinación de la pena aplicable estará dada, en primer lugar, por el marco penal establecido en el artículo $391 \mathrm{~N}^{\circ} 1$ del Código Penal, esto es, presidio mayor en su grado medio a presidio perpetuo (duración de 10 años y un día a perpetuidad). Pero como la LRPA establece que debe aplicarse la pena inferior en un grado al mínimo del señalado por la ley penal de adultos, correspondería imponer, en principio, una sanción cuya duración coincida con la de presidio mayor en su grado mínimo, esto es, 5 años y un día a 10 años, según la escala establecida en el artículo 59 en relación con el artículo 56 del Código Penal. Este será, por consiguiente, el marco penal a partir del cual se determine la extensión concreta y la naturaleza de la sanción que deba imponerse conforme a los artículos 22, 23 y 24 LRPA. Por otro lado, si el mismo delito es cometido por un niño mayor de 14 pero menor de 16 años, no podrá aplicarse una pena privativa de libertad superior a 5 años (art. 18 LRPA), por lo que la sanción deberá rebajarse a lo menos en 2 grados respecto de la mínima prevista para el respectivo delito por la ley penal de adultos conforme lo dispone el inciso $2^{\circ}$ del artículo 22 LRPA.

Sin embargo, basta la mera lectura de la tabla demostrativa contenida en el artículo 23 LRPA, para observar que existen sanciones que, por su naturaleza, no son susceptibles de adaptarse a los tiempos de duración que la ley les asigna. Tales son: la amonestación, la multa y la reparación del daño causado. Por otra parte y aunque la sanción de prestación de servicios en beneficio de la comunidad es, prima facie, divisible en los tiempos de duración que señala el artículo 23 LRPA (1 a 60 días, 61 a 540 días y 
541 días a 3 años), debe considerarse al mismo tiempo que el artículo 11 LRPA establece que ella "tendrá una extensión mínima de 30 horas y máxima de 120 horas", y que "no podrá exceder en ningún caso de 4 horas diarias y deberá ser compatible con la actividad educacional o laboral que el adolescente realice". Ahora bien, si el tribunal aplica 120 horas de prestación de trabajo en servicio a la comunidad a un adolescente por la comisión de un delito cuya pena tiene una duración de 3 años, ¿quiere ello decir que las 120 horas deben distribuirse en tres años? Pareciera absurdo que así fuera y, además, se pondría en peligro la finalidad preventivo especial de la pena, pues se encuentra comprobado criminológicamente que mientras más prolongado es el tiempo de duración de la ejecución de una sanción que depende de la voluntad o posibilidades de quien asume cumplirla, mayor será la probabilidad de incumplimiento de la misma, circunstancia que haría innecesariamente procedentes las reglas sobre quebrantamiento de condena y, en el caso particular del trabajo en servicio a la comunidad, la sustitución de ésta por una sanción superior, no privativa de libertad (art. 11 inciso final LRPA).

Por otro lado, la ley establece un límite temporal absoluto para la pena de libertad asistida especial. En efecto, conforme al inciso final del art. 14 LRPA, la duración de esta sanción "no podrá exceder los tres años". Nos parece evidente que esta restricción dice relación con la finalidad fundamental de la pena en el ámbito de la criminalidad juvenil, cual es apoyar, suplir, promover los procesos de socialización del niño o adolescente (cfr. art. 20 LRPA). La libertad asistida especial es una pena destacadamente apropiada para tal propósito, el que no se obtendrá si la duración de la sanción es extremadamente prolongada o desproporcionada con la gravedad del hecho que reprime. No obstante, y en una aparente inadvertencia del legislador, esta pena se incluye, en la tabla demostrativa contenida el art. 23 LRPA, junto con aquellas que temporalmente pueden extenderse entre $\mathbf{3}$ años y un día a 5 años. Esta situación demuestra que la tabla de extensión punitiva prevista en el artículo 23 LRPA no opera en todos los casos como criterio para la determinación temporal de la sanción aplicable, sino como criterio objetivo para la selección jurisdiccional de la pena aplicable a un caso concreto, después de efectuar las equivalencias con las penas del Código Penal ${ }^{14}$ y los ajustes establecidos por la propia ley.

Por consiguiente, si la extensión de la sanción va desde 3 años y 1 día a 5 años, el juez podrá optar entre la internación en régimen cerrado con programa de reinserción social, la internación en régimen semicerrado con programa de reinserción social o la libertad asistida especial. En los dos primeros casos, la opción determinará además la duración posible de la sanción, pero en el tercer caso, la opción del tribunal estará determinada temporalmente por la norma del inciso final del artículo 14 LRPA, por lo que en caso alguno podrá exceder de 3 años. Esta conclusión es, además, plenamente coincidente con la norma restrictiva prevista en el inciso final del artículo 22 LRPA, respecto de las penas privativas de libertad.

\footnotetext{
${ }^{14}$ En este sentido, resulta particularmente ilustrativa la primera parte de la regla primera del artículo 23 LRPA cuando señala: "[s]i la extensión de la sanción resulta equivalente a una pena de crimen (...)".
} 
Horvitz - Determinación de las sanciones en la ley de responsabilidad penal juvenil...

Otro ejemplo: si la extensión de la sanción oscila entre 61 a 540 días, la opción del tribunal por la internación en régimen semicerrado con programa de reinserción social o la libertad asistida en cualquiera de sus formas determinará, también, la duración de la sanción, pues en este caso no se infringe el art. 14 inciso final LRPA. Sin embargo, la opción por la prestación de servicios en beneficio de la comunidad o la reparación del daño causado no prejuzga la duración misma de la sanción. En efecto, el tribunal podría imponer 30 horas de esta sanción a cumplirse en 30 días o reparar el daño causado en un plazo de 30 días, entre otras posibilidades.

Por las consideraciones precedentes, estimamos que los tiempos de duración de las sanciones sólo operan como tales en el ámbito de aquellas divisibles temporalmente en dichos parámetros, excluyendo la libertad asistida especial cuando la pena excede de tres años. En los restantes casos, la extensión de la sanción opera como criterio objetivo para que el tribunal escoja aquélla más apropiada al caso concreto conforme a las reglas del art. 24 LRPA. Esta distinción nos será de gran utilidad cuando examinemos las reglas de selección de las sanciones conforme a su naturaleza ${ }^{15}$.

\subsubsection{Reglas que operan en un segundo nivel de determinación.}

El inciso $1^{\circ}$ del artículo 22 LRPA establece que la duración o extensión de la sanción (como ya adelantáramos, todavía sin referirse a su naturaleza, la que recién se señala en el artículo 23 LRPA) deberá determinarse aplicando las reglas previstas en el Párrafo $4^{\circ}$ del Título III del Libro I del Código Penal (artículos 50 y siguientes), con excepción de lo dispuesto en el artículo 69 de dicho cuerpo legal. Por su parte, el inciso $2^{\circ}$ del mismo precepto establece que si la sanción calculada en la forma prevista en el inciso $1^{\circ}$ supera los límites máximos dispuestos en el artículo 18, "su extensión definitiva deberá ajustarse a dichos términos".

En un análisis sistemático, las reglas precedentes indican que deberá recurrirse a las contenidas en el Código Penal y en leyes penales especiales para calcular la pena aplicable según la calidad de la participación en el delito (autor, cómplice o encubridor) y el grado de desarrollo del mismo (tentativa, frustración y consumación) y que, en general, determinan una reducción en uno o dos grados de la pena asignada al autor del delito consumado correspondiente (arts. 50-54 CP).

El "grado de pena" a que se refiere la LRPA, por ejemplo en su artículo 21, es una medida temporal de equivalencia con la señalada en el Código Penal, pues en la estructura de sanciones de la nueva ley penal juvenil no tiene recepción expresa. En efecto, la LRPA no contempla tres tramos temporales diferenciados de pena según gravedad (grados máximo, medio y mínimo), como lo hace el Código Penal.

De la observación de la tabla demostrativa que contiene el artículo 23 LRPA se desprende que la extensión de cada una de las penas allí contempladas se corresponde con un grado de una pena divisible de adultos. Esta circunstancia será especialmente

15 Vid. infra 4.2. 
relevante a la hora de interpretar y aplicar las reglas de determinación de pena según número y entidad de circunstancias atenuantes o agravantes, contempladas en los artículos 65 y siguientes del Código Penal. En efecto, debido a la característica precedentemente señalada, tendrá particular incidencia en el ámbito del juego de las circunstancias atenuantes y agravantes que modifican la responsabilidad penal juvenil la regla de determinación de pena contenida en el artículo 67 del Código Penal, porque ella se refiere, justamente, a los casos en que la pena señalada al delito sea un grado de una divisible. Así, si concurre sólo una circunstancia atenuante o sólo una agravante, el tribunal deberá aplicar en el primer caso la pena en su mínimum y en el segundo, en su máximum. Seguidamente la ley señala que para determinar el minimum y el máximum de la pena debe dividirse por mitades el período de su duración: la mitad superior formará el máximum y la mitad inferior, el minimum.

Siguiendo el ejemplo propuesto anteriormente, determinaremos la pena aplicable al adolescente mayor de 16 años, cómplice de un homicidio calificado consumado, a quien favorece una atenuante y ninguna agravante:

$1^{\circ}$ Debe imponérsele la pena inmediatamente inferior al mínimo de la señalada para el respectivo delito (art. $21 \mathrm{LRPA}$ ); en la nomenclatura de la LRPA, una pena cuya extensión vaya de 5 años y un día a 10.

$2^{\circ}$ La pena así determinada debe disminuirse en un grado más atendida la clase de participación en el delito (art. 51 del Código Penal); esto es, a una duración de entre 3 años y un día a 5 años.

$3^{\circ}$ Finalmente, la pena rebajada conforme a las reglas precedentes debe ser impuesta en su grado mínimum (art. 67 del Código Penal), esto es, en el ámbito de la mitad inferior de la pena señalada precedentemente ( 3 años y un día a 4 años).

Ahora bien, como ya expresáramos precedentemente, la fijación de la extensión de la sanción concreta aplicable sólo podrá adaptarse a los parámetros temporales fijados en la tabla del artículo 23 LRPA, cuando se trate de penas privativas de libertad o de libertad asistida en cualquiera de sus formas, excepto en el caso de la regla $\mathrm{N}^{0} 2$ del citado precepto legal, pues la libertad asistida especial en caso alguno puede exceder de 3 años. Sin embargo, ¿qué ocurrirá con las demás sanciones, esto es, aquellas no susceptibles de ser reducidas a estos parámetros temporales? Estimamos que dentro del marco penal determinado por aplicación de la regla del artículo 22 LRPA, el tribunal deberá individualizar la pena respetando las restricciones que impone su naturaleza y los criterios del artículo 24 LRPA, en cuanto sean aplicables.

Así, por ejemplo, el monto de la reparación del daño causado deberá guardar proporción con la gravedad del ilícito de que se trate y no necesariamente con la cuantía del daño ocasionado, pues esta sanción persigue fines públicos relacionados con la función de la pena, en tanto que la reparación civil compensatoria o indemnizatoria de los daños no enteramente satisfecha puede todavía perseguirse por la vía civil (artículo 10 inciso $2^{\circ}$ LRPA). El criterio de "la extensión del mal causado con la ejecución del delito", a que se refiere la letra e) LRPA, dice relación, en primer lugar, con la entidad de la afectación al bien jurídico producido por el delito (puede tratarse de una lesión o una 
Horvitz - Determinación de las sanciones en la ley de responsabilidad penal juvenil...

mera puesta en peligro del mismo ${ }^{16}$; también atiende a las consecuencias perjudiciales del delito, que no siempre serán de carácter económico (daño a un bien de gran valor afectivo) y, para algún sector de la doctrina, comprende asimismo el "daño mediato" o alarma pública que ocasiona el hecho en la comunidad ${ }^{17}$.

Tratándose de la pena de multa, además de los criterios del artículo 24 LRPA, deberán considerarse "la condición y las facultades económicas del infractor y de la persona a cuyo cuidado se encontrare" (artículo 9 inciso $1^{\circ}$ LRPA).

El mismo procedimiento habrá de ocuparse con relación a la prestación de servicios en beneficio de la comunidad, en que su ubicación dentro de un determinado tramo de extensión de pena no predetermina, como vimos en otro lugar ${ }^{18}$, la cantidad de horas de prestación ni el lapso total en que ellas deben verificarse.

\subsubsection{Situación especial de las penas privativas de libertad}

Existe una situación especial de determinación de pena que tiene por consecuencia una notable rebaja en la duración de la sanción con aquella que correspondería -en el sistema penal de adultos- a un injusto relevantemente más grave. En efecto, como el tope máximo de duración de una pena juvenil es de 10 años y 5 años, según la edad del infractor ${ }^{19}$, ocurrirá que si el joven comete un delito que en el Código Penal tuviere asignada penas superiores a 15 años y un día de duración (presidio o reclusión mayores en su grado máximo a presidio perpetuo), el tribunal deberá ajustar las penas de modo que en concreto no sobrepasen los límites establecidos por el artículo 18 LRPA. Así, si un joven de 15 años comete parricidio, le corresponderá prima facie una pena cuya duración oscile entre 10 años y un día y 15 años $^{20}$; pero como es menor de 16 años, la pena jamás podrá exceder de 5 años.

En consecuencia, y aunque no existan circunstancias atenuantes de responsabilidad criminal que permitan rebajar la pena en un grado, dicha rebaja debe operar de pleno derecho por la sola circunstancia de la edad del menor. En el ejemplo dado precedentemente, deben hacerse jugar, primero, las reglas de determinación de pena previstas en el Párrafo $4^{\circ}$ del Título III del Libro I del Código Penal, con excepción de lo dispuesto en el artículo 69 de dicho cuerpo legal. Luego, si la sanción calculada supera los límites máximos dispuestos en el artículo 18 LRPA, su extensión definitiva deberá ajustarse a dichos límites (artículo 22 inciso $2^{\circ}$ LRPA). Pero, además, cuando el artículo 18 limita a un máximo de 5 años la privación de libertad a un joven de 14 ó 15 años, hace inaplicable la regla $1^{\text {a }}$ del artículo 23 LRPA, que se refiere a la naturaleza de las sanciones que se pueden imponer cuando su duración es superior a 5 años y un día ${ }^{21}$.

\footnotetext{
16 Sobre el particular, vid. Etcheberry, A.: Derecho Penal, P.G., T.II, $3^{\text {a }}$ ed., Editorial Jurídica de Chile, Santiago, 1998, p.191.

${ }^{17}$ Etcheberry, cit., p.191.

18 Vid. supra 4.1.2.

19 Vid. artículo 18 LRPA

${ }^{20}$ Cfr. artículo 390 del Código Penal en relación al artículo 21 LRPA.

${ }^{21}$ En el mismo sentido, Berríos, G.: "El nuevo sistema de justicia penal para adolescentes", cit., p. 168.
} 
El tratamiento punitivo más benigno se dispensa a quien, por su edad, está en una situación de menor desarrollo cognitivo y de personalidad, lo que le impide aprehender cabalmente las normas y adecuar su comportamiento a ellas. La finalidad especial del derecho penal juvenil determina, por consiguiente, la imposición de sanciones más "blandas" en cuanto a duración y naturaleza, a fin de favorecer y fortalecer el respeto de las normas y suplir las necesidades de desarrollo e integración social.

Un tratamiento análogo al precedente debe darse al condenado en caso de concurso de delitos, ya sea por las reglas del Código Penal (artículos 74 ó 75) -aplicable a la especie en virtud del inciso $2^{\circ}$ del artículo 1 LRPA- o del Código Procesal Penal (artículo 351) aplicable conforme al inciso $1^{\circ}$ del artículo 27 LRPA.

\subsection{Reglas de determinación de la naturaleza de las penas.}

Sólo una vez que el tribunal ha establecido la duración de la pena en concreto, esto es, considerando las reglas de determinación de pena precedentemente estudiadas, corresponderá aplicar los artículos 23 y 24 LRPA. Por ello, estimamos pertinente distinguir dos fases en el proceso de individualización de la pena aplicable al condenado.

\subsubsection{Primera fase del procedimiento de individualización de la pena}

Para ello es necesario tener en consideración las siguientes normas, reglas y procedimiento:

a) La escala general del artículo $6^{\circ}$ LRPA designa las penas de acuerdo a su naturaleza y las ordena en una escala de gravedad descendente, en la que la más grave es la internación en régimen cerrado con programa de reinserción social y la más leve es la sanción de amonestación. Por su parte, el artículo 23 LRPA contempla cinco marcos penales diferentes, asociada su gravedad a la extensión temporal de los mismos.

b) Cada marco penal contempla dos o más sanciones de igual o diferente naturaleza, confiriéndose al tribunal la facultad de seleccionar una de ellas conforme a las reglas que contiene el artículo 23 LRPA. Así, por ejemplo, si la sanción aplicable tiene un marco penal de tres años y un día a cinco años, el tribunal podrá seleccionar una de entre tres sanciones diferentes disponibles: a) internación en régimen cerrado con programa de reinserción social, b) internación en régimen semicerrado con programa de reinserción social, o c) libertad asistida especial. En cambio, si la extensión de la sanción resulta equivalente a una pena de crimen (artículo 23.1 LRPA), el tribunal sólo puede optar entre dos penas privativas de la pena de libertad: la internación en régimen cerrado o de internación en régimen semicerrado, ambas con programa de reinserción social. 
Horvitz - Determinación de las sanciones en la ley de responsabilidad penal juvenil...

c) El inciso final del artículo 26 LRPA estipula que "en ningún caso se podrá imponer una pena privativa de libertad si un adulto condenado por el mismo hecho no debiere cumplir una sanción de dicha naturaleza". Esta norma alude indirectamente a la posibilidad de sustitución de una pena privativa de libertad por alguna de las medidas que contempla la Ley 18.216. Como es sabido, dicho cuerpo legal permite suspender la ejecución de las penas privativas o restrictivas de la libertad impuestas en una sentencia, en el caso de la remisión condicional de la pena y de la libertad vigilada, o sustituirla por la reclusión nocturna, en general, cuando la duración de aquellas no excede de 5 años (en el caso de la libertad vigilada) o de 3 años (en los demás casos). Por consiguiente, bajo ningún supuesto podrá aplicarse judicialmente la pena de internación en régimen cerrado o semicerrado de privación de libertad (consideradas sanciones privativas de libertad en el art. 15 LRPA), cuando la pena aplicable no supere los cinco años de duración y el condenado cumpla con los requisitos exigidos por la Ley 18.216 para poder acceder a alguna de las medidas alternativas que dicho cuerpo legal contempla ${ }^{22}$. Así, por ejemplo, si la duración de la pena aplicable cae en el ámbito de las reglas $2^{\mathrm{a}}, 3^{\mathrm{a}}$ ó $4^{\mathrm{a}}$ del artículo 23 LRPA y el condenado reúne los requisitos de la Ley 18.216, el juez deberá optar por cualquier otra pena que no sea la internación en régimen cerrado o semicerrado, con programa de reinserción social.

d) A la situación descrita precedentemente se suma que el artículo 41 LRPA autoriza al tribunal, en ciertos casos, para disponer la suspensión de la imposición de la condena que emita en su sentencia. En efecto, en los casos que "hubiere mérito para aplicar sanciones privativas o restrictivas de libertad iguales o inferiores a 540 días, pero concurrieren antecedentes favorables que hicieren desaconsejable su imposición, el juez podrá dictar sentencia y disponer en ella suspensión de la pena y sus efectos por un plazo de seis meses". El cumplimiento del plazo sin que el imputado sea objeto de un nuevo requerimiento o formalización de la investigación dará lugar al sobreseimiento definitivo de la causa.

e) Por otro lado, la ley señala que en los casos en que fuere procedente la internación en régimen cerrado o semicerrado, ambas con programa de reinserción social, el tribunal podrá imponer complementariamente una pena de libertad asistida en cualquiera de sus formas, por un máximo que no supere el tiempo de la condena principal (artículo 19 LRPA). La ley señala la forma en que se ejercerá esta facultad por parte del tribunal: i) con posterioridad a la ejecución de la pena privativa de libertad, siempre y cuando en total no se supere la duración máxima de ésta (complementariedad); o ii) en forma previa a la ejecución de la pena privativa de libertad, lo que determina que la pena principal quede en suspenso y en carácter condicional para ejecutarse en caso de incumplimiento de la libertad asistida en cualquiera de sus formas, en el caso de las penas que se extienden hasta 540 días. En este último caso, la libertad asistida opera al modo de la

\footnotetext{
${ }^{22}$ Esto es, los requisitos contenidos en los artículos 4, 8 y 15 de la Ley 18.216.
} 
probation anglosajona ${ }^{23}$, instituto que ha sido recogido en nuestro ordenamiento jurídico en ciertas medidas alternativas a las penas privativas de libertad previstas en la Ley 18.216 y en la suspensión condicional del procedimiento que recoge el Código Procesal Penal ${ }^{24}$. De estas reglas se desprende que la libertad asistida, en cualquiera de sus formas, deberá aplicarse en forma previa cuando la duración de la sanción se ubique en el tramo que contempla el numeral $4^{\circ}$ del artículo 23 LRPA. En los demás casos (reglas $1^{\mathrm{a}}, 2^{\mathrm{a}}$ y $3^{\mathrm{a}}$ ), la libertad asistida debiera aplicarse con posterioridad a la pena privativa de libertad. En nuestra opinión, el art. 19 operaría también en el ámbito de la regla $1^{a}$ del artículo 23 LRPA, aun cuando ella no contempla la libertad asistida como sanción aplicable, pues la norma del artículo 19 es general y se refiere a los casos "en que fuere procedente la internación en régimen cerrado o semicerrado, ambas con programa de reinserción social", sin hacer distinciones. Se trata de una forma de mitigar la excesiva aflictividad de una pena grave, cuando se requiera un tratamiento especializado en el medio libre respecto de un joven que tiene un pronóstico favorable de reinserción social.

f) El inciso $1^{\circ}$ del artículo 25 LRPA señala que "en las situaciones regladas en los numerales 3 y 4 del artículo 23, el tribunal podrá imponer conjuntamente dos de las penas que las mismas reglas señalan, siempre que la naturaleza de éstas permita su cumplimiento simultáneo". Esto es, sólo en estos dos tramos punitivos el tribunal puede imponer sanciones combinadamente o en forma mixta $^{25}$, respetando el límite máximo de extensión de pena allí señalados, siempre que ello permita el mejor cumplimiento de las finalidades preventivo especiales que señala el artículo 20 de la ley y así se consigne circunstanciadamente en resolución fundada (artículo 25 inciso $2^{\circ}$ LRPA). Esta norma está en la línea político-criminal existente en el derecho comparado que plantea la necesidad de individualizar la pena buscando una combinación de aquellas que resulte más apropiada al fin de reintegración social y que evite, en lo posible, los procesos de desocialización que conllevan las penas de encierro. El límite de aplicación del artículo 25 LRPA debe ser matizado, pues como vimos a propósito de las sanciones mixtas que prevé el artículo 19 del mismo cuerpo legal, la libertad asistida en cualquiera de sus formas también puede ser aplicada en combinación o complementariamente con las penas privativas de libertad que contempla la ley. Sólo que ella establece la forma en que debe producirse su combinación.

\footnotetext{
23 La probation, institución de origen anglosajón, designa todas aquellas instituciones que suponen la suspensión de la ejecución de una pena, de la sentencia o del proceso penal sujeto a ciertas condiciones que deben cumplirse en un lapso de prueba o de observación. Si se satisfacen las condiciones impuestas en dicho lapso, no se ejecuta la pena, no se dicta la sentencia o se extingue la acción penal para perseguir las correspondientes responsabilidades penales. También véanse los artículos. 41 y 54 de la LRPA.

${ }^{24}$ Cfr. Párrafo $6^{\circ}$ del Título I del Libro II del Código Procesal Penal; asimismo, Horvitz/López: Derecho procesal Penal chileno, T.I, Editorial Jurídica de Chile, Santiago, 2002, pp. 552 y ss.

${ }^{25}$ Existen modelos en el derecho comparado que contempla este tipo de sanciones mixtas o combinadas, como en el caso del Reino Unido, con la introducción de la Ley de Justicia Criminal de 1991, primero, y de 1999, después (Ley sobre Justicia Juvenil y Evidencia Criminal).
} 
Horvitz - Determinación de las sanciones en la ley de responsabilidad penal juvenil...

\subsubsection{Segunda fase del proceso de individualización}

La selección de la pena juvenil aplicable no es discrecional del órgano jurisdiccional. La ley impone al tribunal el deber de atender a los criterios señalados en el artículo 24 LRPA para decidir la naturaleza de la sanción que corresponda al caso concreto, "dejando constancia de ello en su fallo".

Tales criterios dicen relación, en parte, con aquellos que debieron considerarse ya antes, para la decisión acerca de la extensión temporal de la sanción, como los contenidos en las letras b) del artículo 24 LRPA, referido al grado de participación en el delito e iter criminis y c), referido a la concurrencia de circunstancias modificatorias de responsabilidad criminal. Dicha valoración tiene, sin embargo, una función diferente en este caso, pues ya no opera para determinar la extensión de la pena, sino para seleccionar la naturaleza de la misma.

Sin perjuicio de la aclaración anterior, estimamos que algunos factores o criterios legales jamás debieron establecerse como tales para determinar la clase de pena aplicable; primero, por afectarse en algún caso el principio de prohibición de doble valoración y de ne bis in idem y, en segundo lugar (o especialmente), porque en la determinación de la naturaleza de la sanción aplicable sólo debió considerarse aquella más adecuada y efectiva al caso concreto desde la perspectiva del fin de prevención especial de la pena. El razonamiento precedente tiene, sin embargo, una mayor importancia tratándose de las penas divisibles temporalmente en los marcos de extensión que establece el artículo 23 LRPA -como las privativas de libertad o la libertad asistida en todas sus formas- que respecto de aquellas no susceptibles de tal división temporal. Nos referiremos, en primer término, a las primeras.

La ley establece como primer criterio "para determinar la naturaleza de las sanciones, dentro de los márgenes antes establecidos" (...) "la gravedad del ilícito de que se trate" (art. 24 letra a) LRPA). Sin embargo, cuando el legislador establece el marco penal de extensión o duración de la pena aplicable fija también objetivamente las posibles penas que, dentro de ese marco temporal, pueden ser seleccionadas por el tribunal. Al incluirlas en él ba debido considerar la gravedad del ilícito de que se trata, pues no se contemplan penas de leve contenido aflictivo dentro de marcos temporales prolongados o extensos, ni viceversa. En efecto, la extensión de la pena “juvenil”" está en relación con la duración de la pena correspondiente de adultos, y ésta, a su vez, con la entidad del bien jurídico y la magnitud de su afectación, y demás factores que atingen a la culpabilidad del autor. De allí que todas aquellos aspectos, elementos o circunstancias que fundan el ilícito, esto es, que han sido tomados en consideración por el legislador al configurar el tipo penal y la extensión de la pena no pueden ser valorados nuevamente en un sentido desfavorable al reo- para seleccionar, esta vez, la clase o naturaleza de la sanción aplicable. Más aun si lo que se persigue con la diversidad de penas en este ámbito es favorecer la reinserción social del adolescente y no fines meramente retributivos (ya considerados al determinarse la extensión de la pena), lo que viene por lo demás impuesto por el artículo 20 LRPA. 
Existe además un argumento histórico que nos permite reafirmar el planteamiento precedentemente expuesto. En efecto, en el artículo 24 del Anteproyecto de Ley sobre Responsabilidad por Infracciones Juveniles a la Ley Penal ${ }^{26}$ se contenía una norma que también atendía a la gravedad de la infracción ya "para determinar la medida aplicable a un joven, como asimismo, para fijar su extensión temporal o cuantía (...)", la que debía ser "evaluada en conformidad con los criterios establecidos en el artículo siguiente (...)". Y el artículo 25 disponía que "para evaluar la gravedad del hecho cometido, el tribunal deberá determinar, en primer lugar, si éste corresponde a una simple infracción o a una infracción grave, de acuerdo a lo dispuesto en el artículo 6 de la presente ley". El mismo precepto legal facultaba al tribunal para considerar los restantes factores actualmente previstos en el art. 24 LRPA, pero tanto para determinar la naturaleza como la extensión de la pena. En el esquema de dicha regulación tal procedimiento era perfectamente posible, tanto porque el Anteproyecto contemplaba un catálogo taxativo y reducido de delitos propiamente "juveniles", como porque distinguía entre infracciones graves y simples, criterio que servía tanto de límite a la imposición de ciertas penas cuanto de fundamento para la determinación de la naturaleza y, junto con ella, de la extensión de la sanción aplicable.

Como es sabido, la distinción entre infracciones graves y simples se mantuvo en el Proyecto de Ley, pero sin resolver los criterios de determinación de la pena concreta aplicable. De allí que finalmente se adoptara un modelo amplio, con remisión a las reglas y nomenclatura del Código Penal, pero adaptado en lo que dice relación con la extensión y naturaleza de las sanciones. Los problemas interpretativos surgen, en lo fundamental, de dos fuentes. El primero se deriva de la circunstancia de haberse desechado la distinción operativa entre infracciones graves e infracciones simples del modelo original, la que pretendía básicamente reservar las penas privativas de libertad para las pocas infracciones graves que se contemplaban en él. Como sabemos, la LRPA contempla penas privativas de libertad no sólo para los crímenes, sino también para los simples delitos en toda su escala, por lo que la distinción perdió su funcionalidad. En segundo lugar, al contemplarse los mismos factores en dos fases distintas de determinación de la pena (primero, para fijar su extensión; después, para fijar su naturaleza) no sólo se plantea la eventual infracción del principio non bis in ídem, sino que se tienden a confundir los niveles en que operan las distintas funciones de la pena en el ámbito de la criminalidad juvenil, confiriéndose un aparente privilegio a los fines retributivos por sobre los fines preventivo-especiales, en abierta infracción del artículo 20 LRPA.

Así, si el menor infractor comete un delito que determinará -conforme a las circunstancias concretas del caso- la aplicación de una pena de crimen, la gravedad del ilícito ya se encuentra valorada y considerada en las reglas de determinación de la pena que fijan la extensión de la sanción y de las penas aplicables en dicho marco temporal, el que excluirá la posible aplicación de penas de distinta naturaleza que las incluidas en el correspondiente tramo de duración de pena. La gravedad del delito, por consiguiente, no debería predeterminar la naturaleza de la sanción aplicable, selección que debería estar orientada fundamentalmente por directrices preventivo-especiales. En tal sentido nos

\footnotetext{
${ }^{26}$ Vid. nota 1.
} 
Horvitz - Determinación de las sanciones en la ley de responsabilidad penal juvenil...

parece altamente acertado el criterio señalado en la letra f) del art. 24 LRPA, de evidente connotación resocializadora, esto es, por "la idoneidad de la sanción para fortalecer el respeto del adolescente por los derechos y libertades de las personas y sus necesidades de desarrollo e integración social". No favorece esta finalidad la selección obligatoria de una pena privativa de libertad para los delitos más graves, especialmente cuando el tribunal no la considere apropiada preventivo-especialmente en el caso concreto.

Con relación a los restantes criterios de determinación de la naturaleza de las sanciones contenidos en el artículo 24 LRPA se pueden realizar similares reflexiones. En efecto, al determinarse la extensión de la pena al hecho concreto también se habrán valorado ya las circunstancias agravantes de la responsabilidad criminal (artículo 24 letra c) LRPA), la forma de participación del menor en el hecho y el grado de desarrollo del delito (art. 24 letra b) LRPA). Por ello, estimamos que estos criterios no deben ser considerados nuevamente para seleccionar la pena aplicable atendiendo a la "gravedad" de su naturaleza (si se acepta que ellas están establecidas en cada tramo en un orden de gravedad descendente) sino sólo en su idoneidad preventivo-especial al caso concreto.

Especial interés tiene el criterio señalado en letra d) del art. 24 LRPA consistente en "la edad del adolescente infractor". En efecto, ¿qué incidencia pretende el legislador que tenga en la designación de la clase de pena aplicable? Tal criterio ya tiene importancia para la determinación del límite máximo de las penas privativas de libertad de conformidad con el artículo 18 LRPA. ¿Quiere decir ello que los infractores mayores de 16 y menores de 18 deberán siempre ser acreedores de las penas de naturaleza más grave respecto de los niños menores de 16 y mayores de 14 años? Como se aprecia, nuevamente retornamos a la discusión sobre la improcedencia de valorar dos veces ciertas circunstancias para agravar la situación punitiva del menor, lo que ocurrirá cuando ellas sirvan para determinar la extensión de la pena y, dentro de su marco, seleccionar aquella de naturaleza más aflictiva. A nuestro juicio, la edad del adolescente sólo podría ser interpretada en un sentido favorable al mismo, esto es, mientras más joven debe optarse por las penas menos aflictivas y menos desocializadoras, pues está demostrado criminológicamente que mientras más precoces son los contactos diferenciales con fuentes criminógenas más pronto, rápido y definitivo será el inicio y consolidación de la carrera criminal ${ }^{27}$.

Ahora bien, ¿qué ocurre con las sanciones que son indivisibles o no son divisibles temporalmente conforme a los marcos penales definidos en el artículo 23 LRPA? Nos referimos específicamente a la amonestación, la multa, la reparación del daño causado y la prestación de servicios en beneficio de la comunidad.

Estimamos que, respecto de estas sanciones, son aplicables sin restricciones los criterios establecidos en el artículo 24 LRPA, no sólo respecto de su naturaleza sino también con relación a su cuantía específica. En efecto, su aplicación se encuentra restringida por la ley a hipótesis de hasta 3 años de extensión de pena. Su previsión o

\footnotetext{
27 Sobre Edwin Sutherland y la teoría de los contactos diferenciales, vid. Anitua, G.: Historias de los pensamientos criminológicos, Editorial del Puerto, Buenos Aires, 2005, pp. 300 y ss.
} 
inclusión en los correspondientes marcos penales no resulta completamente del procedimiento establecido en el artículo 22 LRPA, pues no se ve cómo, respecto de ellas, podría hacerse una analogía estricta, compatible con su estructura y naturaleza. En efecto, si se determinara una pena concreta de 540 días, ¿qué extensión cabría atribuirle a la multa o la reparación del daño? Por ello resultan relevantes los criterios del artículo 24 LRPA, disposición que es expresamente invocada por el artículo 9 LRPA para la determinación del monto o cuantía de la multa, lo que ratifica nuestro planteamiento de que tales criterios sirven no sólo para seleccionar la naturaleza de la sanción aplicable, sino también para la determinación de la cuantía de la misma cuando nos encontramos frente a esta clase de sanciones.

En definitiva, sólo en el caso de estas penas no existirá una doble valoración prohibida, esto es, en un sentido desfavorable al reo. Así, en el marco temporal que va de 1 a 60 días, sería perfectamente lícito optar por una de las 4 sanciones allí previstas (art. $23 \mathrm{~N}^{\circ} 5$ LRPA) y determinar su cuantía en base a los criterios el artículo 24 LRPA. De este modo, el tribunal podría escoger la prestación de servicios en beneficio de la comunidad atendiendo a la gravedad del ilícito cometido, su participación en él y las circunstancias modificatorias de responsabilidad concurrentes y fijar su extensión en 30 horas, en atención a la edad del infractor, la extensión del mal causado y la idoneidad de la sanción para favorecer su integración social.

\section{Procedimientos aplicables al ámbito sancionatorio juvenil}

\subsection{Regla general}

Conforme al inciso $1^{\circ}$ del artículo 27 LRPA, "la investigación, juzgamiento y ejecución de la responsabilidad por infracciones a la ley penal por parte de adolescentes se regirá por las disposiciones contenidas en la presente ley y supletoriamente por las normas del Código Procesal Penal". No obstante, y como veremos, las normas procesales de la LRPA son escasas; de modo que la regla general será la aplicabilidad de las normas del Código Procesal Penal.

Por consiguiente, no existiendo una norma especial en contrario, son aplicables al joven imputado instituciones procesales generales previstas en el Código Procesal Penal como el principio de oportunidad (en los términos del artículo 35 LRPA), la suspensión condicional del procedimiento (a que se alude en el inciso final del art. 41 LRPA), el procedimiento simplificado y monitorio, etc. Problemática nos parece la posibilidad de realizar acuerdos reparatorios en el ámbito de aquellos niños o adolescentes que, conforme a la ley civil, no tengan capacidad de disposición, a menos que comparezca su representante legal o apoderado.

Con respecto al procedimiento abreviado, estimamos que el menor desarrollo cognitivo y de madurez del menor debiera llevar a proceder con mucha cautela en este

ámbito. Recuérdese que se trata de un procedimiento que requiere el consentimiento del imputado, "libre y con pleno conocimiento de sus derechos" (artículo 241 del Código 
Horvitz - Determinación de las sanciones en la ley de responsabilidad penal juvenil...

Procesal Penal). El carácter coactivo del proceso penal ${ }^{28}$ y la mayor vulnerabilidad del menor en su proceso de desarrollo debiera conducir al rechazo del procedimiento abreviado en todos aquellos casos en que, por su edad o su proceso de desarrollo, denote una falta de comprensión cabal de sus derechos y de las consecuencias jurídicas de su consentimiento.

\subsection{Regla especial}

El inciso $2^{\circ}$ del artículo 27 LRPA establece que "el conocimiento y fallo de las infracciones respecto de las cuales el Ministerio Público requiera una pena no privativa de libertad se sujetará a las reglas del procedimiento simplificado o monitorio, según el caso, regulados en el Título I del Libro IV del Código Procesal Penal.”

Existe constancia en la tramitación parlamentaria sobre la necesidad de contemplar un procedimiento simple y breve en los casos de delitos menos graves, que impidiera la prolongación indebida de los procesos y que pudiera resolverse inmediatamente con sanciones no privativas de libertad ${ }^{29}$. Es evidente, desde esta perspectiva, que con esta norma sólo se quiso ampliar el ámbito de aplicación del procedimiento simplificado respecto del previsto en el artículo 388 del Código Procesal Penal. Otra interpretación implicaría excluir la aplicación del procedimiento simplificado a casos en los que, en el sistema penal de adultos, sería completamente admisible, generando una discriminación infundada en perjuicio del joven. La contemplación de procedimientos expeditos para juzgar delitos poco complejos y menos graves ha encontrado su fundamento de legitimidad en el derecho del imputado a ser juzgado dentro de un plazo razonable o sin dilaciones indebidas.

La necesidad del procedimiento simplificado resultaba también inevitable en el ámbito punitivo juvenil, ante la gran cantidad de delitos de bagatela que debe enfrentar cualquier sistema de justicia criminal hoy en día. Su enjuiciamiento en todos los casos conforme a las reglas del procedimiento ordinario resulta imposible ${ }^{30}$, y no parece apropiado desde el punto de vista del principio de proporcionalidad. Sin embargo, no deben desoírse los reclamos que contra ellos suele formular la doctrina, entre los cuales están los siguientes: las penas serían pronunciadas de forma precipitada y sin que el imputado sea oído suficientemente; los afectados no se defienden contra pronunciamientos injustos por los motivos más diversos (indiferencia, ignorancia, temor); los fiscales y los tribunales prefieren estos procedimientos para ahorrarse trabajo y los primeros solicitan intencionalmente penas bajas para evitar la oposición del

\footnotetext{
28 Sobre este punto, vid. Horvitz/ López, Derecho procesal penal chileno, T.II, Editorial Jurídica de Chile, Santiago, 2004, pp. 503 y ss.

${ }^{29}$ Cfr. Indicación No 121, del Presidente de la República, de la que se da cuenta en el Segundo Informe de la Comisión de Constitución, Legislación, Justicia y Reglamento del Senado, recaído en el proyecto de ley, en segundo trámite constitucional, que establece un sistema de responsabilidad de los adolescentes por infracciones a la ley penal. Boletín 3.021-07.

${ }^{30}$ En este sentido, expresamente, Roxin, Derecho procesal penal (trad. G. Córdoba y D. Pastor), Editores del Puerto, Buenos Aires, 2003, pp. 550-551.
} 
imputado $^{31}$. Estas críticas deben ser ponderadas debidamente, atendida la incidencia en la utilización de estos procedimientos en el conjunto del sistema y la mayor vulnerabilidad de los adolescentes frente al proceso penal y la intervención punitiva estatal.

En definitiva, el procedimiento simplificado se aplicará, en nuestra opinión:

a) Respecto de hechos punibles constitutivos de alguna de las faltas a que se refiere el inciso $2^{\circ}$ del artículo $1^{\circ}$ LRPA, esto es, las faltas cometidas por adolescentes mayores de 16 años contempladas en los artículos $494 \mathrm{~N}^{\circ}$ s 1, 4, 5 y 19, sólo en relación con los artículos 477, 494 bis, $495 \mathrm{~N}^{\circ} 21$ y $496 \mathrm{~N}^{\circ}$ s 5 y 26, del Código Penal y las tipificadas en la Ley 20.000 .

b) Respecto de hechos punibles (infracciones) para los cuales el Ministerio Público requiera una pena no privativa de libertad (artículo 27 inciso $2^{\circ}$ LRPA). Deben considerarse no privativas de libertad, todas aquellas penas a que se refiere el Párrafo $2^{\circ}$ del Título I de la LRPA, que se intitula "[d]e las sanciones no privativas de libertad", a saber: amonestación, multa (en que debe aplicarse el procedimiento monitorio), reparación del daño, servicios en beneficio de la comunidad, prohibición de conducir vehículos motorizados, libertad asistida y libertad asistida especial.

c) Respecto de hechos punibles para los cuales el Ministerio Público requiera la imposición de una pena privativa de libertad cuya extensión no supere los 540 días (equivalente al umbral máximo del presidio o reclusión menores en su grado mínimo a que se refiere el artículo 388 del Código Procesal Penal) de duración concreta, esto es, habiéndose hecho operar la regla de pena contenida en el artículo 21 LRPA y las reglas de determinación de la pena contempladas en el Párrafo $4^{\circ}$ del Título III del Libro I del Código Penal, con excepción de lo dispuesto en el artículo 69 del mismo cuerpo legal (artículo 22 inciso $1^{\circ}$ LRPA). Mediante este procedimiento se llegará a la regla contenida en el numeral $4^{\circ}$ del artículo 23 LRPA, que establece las penas aplicables en el rango de extensión que va desde 61 a 540 días. Si conforme a dicha regla, el Ministerio Público requiere la imposición de una sanción privativa de libertad (internación en régimen semicerrado con programa de reinserción social) y el tribunal juzga fundada dicha solicitud, deberá dar curso al caso conforme a las reglas del procedimiento simplificado.

La afirmación precedente nos conduce a discutir sobre la cuestión de cómo se determina el procedimiento aplicable; si en base a la mera solicitud del Ministerio Público o en base al mérito de los antecedentes de la investigación o del requerimiento, los que podrían ser controlados por el tribunal a solicitud de alguno de los intervinientes. Esta interrogante ya se nos planteó respecto del sistema penal de adultos ${ }^{32}$, y estimamos que la misma respuesta debe darse en este caso.

\footnotetext{
${ }^{31}$ Schmidt-Hieber, citado por Roxin, cit., p. 550.

32 Vid. Horvitz, M.I. en Horvitz/López, Manual de derecho procesal penal chileno, T.II, cit., pp. 459 y ss.
} 
Horvitz - Determinación de las sanciones en la ley de responsabilidad penal juvenil...

En efecto, este procedimiento especial no sólo es aplicable a las faltas, sino también a los hechos constitutivos de simples delitos para los cuales el ministerio público requiera la imposición de una pena que no exceda de 540 días de extensión de pena. Como se dijo, se trata de la pena en concreto solicitada por el órgano de persecución penal, ya sea al momento de la acusación-si el caso hubiere sido iniciado conforme a las reglas del procedimiento ordinario- o en su requerimiento, si el caso hubiere comenzado directamente de acuerdo con las normas del Título I del Libro IV del Código Procesal Penal.

En el Proyecto del Ejecutivo del nuevo Código Procesal Penal sólo se contemplaba la aplicación del procedimiento simplificado para las faltas; por ello se denominaba -al igual que en el sistema antiguo- "procedimiento por faltas". Sin embargo, durante la tramitación parlamentaria se hizo presente la conveniencia de ampliar su aplicabilidad "a delitos menores, que constituyen el mayor número de delitos y que recargarían en demasía a los tribunales orales", añadiéndose otras consideraciones utilitarias como el carácter "complejo y caro" del juicio oral, "innecesario en estos delitos que, en muchos casos, quedarían dentro del principio de oportunidad del ministerio público" "33. En otros casos, sería necesario llevarlas a juicio por razones preventivogenerales, esto es, "como una forma de que la ciudadanía se sienta protegida y vea que hay una sanción rápida" 34 .

La inclusión de ciertos simples delitos dentro del ámbito de aplicación del procedimiento simplificado ha sido fuente de importantes problemas interpretativos, por la coexistencia con otros procedimientos aplicables al ámbito de los simples delitos, especialmente con el procedimiento ordinario. Como una forma de fomentar su utilización, la legislación especial tiende, en forma creciente, a hacer aplicables los procedimientos simplificado y monitorio, "cualquiera sea la pena solicitada por el fiscal" 35 . Es importante destacar, sin embargo, que en estos casos, el legislador delimita previamente el ámbito respecto del cual se podrá hacer aplicación del procedimiento simplificado o monitorio; así, por ejemplo, el artículo $196 \mathrm{~F}$ de la Ley del Tránsito establece que "tratándose del procedimiento por faltas, el fiscal podrá solicitar la aplicación del procedimiento monitorio (...) cualquiera fuere la pena cuya aplicación requiriere. Si el juez de garantía resuelve proceder de conformidad con esta norma, reducirá las penas aplicables en la proporción" que señala la letra c) del art. 392 CPP. Como se observa, la fórmula "cualquiera sea la pena solicitada" alude a la diferente naturaleza de las penas previstas para las faltas, que pueden no consistir (únicamente) en "multa" o "prisión". Se trata, en consecuencia, de hacer aplicables los procedimientos simplificado y monitorio a hechos constitutivos de faltas o simples delitos cuyas penas no consistan, o al menos no únicamente, en multa (art. 392 CPP) o prisión (art. 395 CPP). Como se observa, esta tendencia se muestra también en la LRPA, al ampliar la

\footnotetext{
33 PFEFFER, Código Procesal Penal, cit., p. 377. En todo caso, la argumentación incurre en una falacia naturalista, pues de estos problemas prácticos no se puede derivar la inconveniencia de someter estos casos a la regla general de enjuiciamiento, sino sólo en base a consideraciones normativas, valorativas.

${ }^{34}$ PFEFFER, cit., p. 378.

${ }^{35}$ Vid., por ejemplo, el artículo $196 \mathrm{~F}$, inciso $2^{\circ}$, de la Ley 18.290, del Tránsito y el artículo 54 de la Ley 19.925, de Alcoholes, por la remisión al artículo 196 F de la Ley del Tránsito, etc.
} 
aplicación de los procedimientos simplificado y monitorio a delitos en que la pena aplicable es de distinta naturaleza a la privativa de libertad.

La problemática referida al procedimiento aplicable se producirá en casos de simples delitos con investigación previa. En efecto, si el procedimiento ha comenzado conforme a las reglas del procedimiento ordinario pero en su transcurso la pena que resulte aplicable al hecho se encuadra en el ámbito del rito simplificado, el ministerio público podría decidir continuarlo conforme a las reglas de este procedimiento especial u optar, lisa y llanamente, por la continuación del caso en procedimiento ordinario. Esta situación podría plantearse en cualquier momento de la etapa de investigación, aunque desde un principio podría dársele tramitación conforme a las normas contenidas en el Título I del Libro IV del CPP.

No obstante, si decide acusar y requerir una pena concreta no superior a 540 días de privación de libertad, el tribunal deberá ordenar la tramitación del caso en conformidad a las reglas del procedimiento simplificado, excluyéndose la posibilidad de continuar su prosecución con arreglo al procedimiento ordinario. En nuestra opinión, la aplicación del procedimiento simplificado es obligatoria, porque existe una norma de procedimiento -de orden público- que así lo ordena, a saber, el inciso $2^{\circ}$ del artículo 388 del Código Procesal Penal, al que hace remisión el inciso $1^{\circ}$ del artículo 27 LRPA. El carácter imperativo de la disposición se verifica cuando señala: "El procedimiento se aplicará....". El fiscal tiene una gran variedad de posibilidades para dar un tratamiento procesal individualizado al caso, según sus características y la pena asignada al delito de que se trata; no obstante, no puede elegir el procedimiento específico conforme al cual debe resolverse el caso. Incluso en el procedimiento abreviado el fiscal no tiene un poder discrecional autónomo: existe un importante control jurisdiccional sobre sus presupuestos de aplicación y se requiere la voluntad del imputado.

Es cierto que el Ministerio Público tiene, en algunos casos, cierta discrecionalidad para calificar el delito y estimar concurrentes o no las circunstancias modificatorias de responsabilidad criminal, pero ello puede y debe ser controlado por el juez de garantía al momento en que se plantea la acusación o se interpone requerimiento en contra del imputado. El tribunal no puede constituir, conforme al modelo constitucional de jurisdicción, un mero buzón de las decisiones, las que podrían ser equivocadas sobre aspectos relevantes en la determinación del procedimiento aplicable al caso. El procedimiento simplificado está previsto para infracciones no graves o en que la pena aplicable no es privativa de libertad; ello justifica la celeridad o cierta merma de las garantías del debido proceso ${ }^{36}$. Pero ello no corresponde cuando se trata de delitos más graves, aunque la pena solicitada por el Ministerio Público sea más leve que la que corresponda conforme a los antecedentes del proceso.

\footnotetext{
${ }^{36}$ Cfr. Las críticas a este procedimiento desde la perspectiva de las garantías del juicio oral, en Horvitz, en Horvitz/López, Derecho Procesal penal chileno, T. II, cit, pp. 490 y ss.
} 